\title{
Review Of Literature For Leadership Attributes In Various Industry
}

\author{
K. Lavanya ${ }^{a}$, Dr. Rajesh Sharma ${ }^{b}$ \\ a Research Scholar, Dept. of Management, \\ Sri Satya Sai University of Technology \& Medical Sciences, Sehore, Bhopal Indore Road, Madhya Pradesh, India \\ ${ }^{\mathbf{b}}$ Research Guide, Dept. of Management, \\ Sri Satya Sai University of Technology \& Medical Sciences, Sehore, Bhopal Indore Road, Madhya Pradesh, India
}

Article History: Received: 11 January 2021; Accepted: 27 February 2021; Published online: 5 April 2021

\begin{abstract}
Leadership can be defined in different ways that it is hard to come up with a single working definition. Leadership is not just a person or group of people in a high position. Leadership is a process in which leader is indulged in various activities to achieve any goal. Leadership refers to the behaviour / attitude of a leader to collect and direct the individuals towards any goal. Leadership is a communication process of leader and individuals. So the effectiveness of an organization depends upon the effective leader and effective leader is that person who has an effective leadership style. Leadership is a very important factor for any organization or group.
\end{abstract}

\section{Introduction}

The worldwide financial crisis has brought about a rush of extraordinary difficulties to the world's monetary and political request. In a circumstance of disturbance, the one key factor that can have an effect, through premonition and ability, is Leadership. Nonetheless, as this examination was started and test began, to acquire theoretical clearness, the outcomes are puzzling. The quest for the correct definition has been age-old. As indicated by Bass and Avolio, a solitary explicit meaning of leadership is an extremely mind boggling task as writing and studies on this theme are shifted and there is no definition that is broadly and generally acknowledged. A few definitions depict leadership as a demonstration of impact, some as a cycle but then others have taken a gander at an individual's attribute characteristics.

Groundbreaking style of Leadership includes the parts of glorified impact, motivation, scholarly incitement and individualized thought and has been recommended generally as the ideal style for overseeing change. Bass, Waldman, Avolio, and Bebb found that leaders scoring higher on Transformational Leadership factors have supporters who show more prominent degrees of groundbreaking practices. The objective of groundbreaking leadership is to "change" individuals and associations from an exacting perspective - to transform them as a main priority and heart; expand vision, knowledge, and comprehension; explain purposes; make conduct consistent with convictions, standards, or values; and achieve changes that are lasting, self-propagating, and force building.

Idealized Influence-Attributes (II-A): This quality of Leadership is related to the building of trustworthiness by the Leaders in their subordinates.

Idealized Influence-Behaviour (II-B): This quality of Leadership always thinks about values, faiths and ethical perspective of the decisions. The Leader practices highly integrated behaviour.

Inspirational Motivation (IM): This quality of Leadership inspires the subordinates and group for the better performance in the organisation.

Intellectual Stimulation: This quality of Leadership encourages innovativeness in subordinates to solve the problems in new ways.

Individual Consideration(IC): This quality of Leadership takes care of the concerns and needs of the subordinates for their development.

\section{Review of Literature}

Jim Allen McCleskey (2014) shows three compelling leadership hypotheses and their development. Investigation of current articles on all the hypotheses is embraced. In this article leadership development hypotheses are likewise talked about. This investigation recommended the measures for scholastic just as down to earth utilization of the outcomes determined in the examination work. Bass expressed that Transactional business elements advance as Transformational as the current pioneers are more imaginative, inventive and assenting. (Bass, 2008). The Leadership speculations are advancing from totalitarian to popularity based viewpoints. Leadership experts should keep on watching the connections among change and adequacy, affiliations among the Leaders and the adherents. That is both the future test and the chronicled past of leadership.

OtaroghenePeretomode (2012) clarified the significance of Leadership in associations. The importance and highlights of the Leadership are additionally examined and how the Leadership is unique in relation to the administration is likewise clarified. Leadership hypotheses and general categorisation like Classical, Behavioral, 
and Contingency is referenced. Need to comprehend the distinction between situational Leadership and possibility speculations is additionally examined. The likenesses and qualifications among the situational leadership and possibility leadership are likewise clarified. Instances of situational leadership are likewise clarified. Defender's decisions about undertaking focused and relationship arranged styles are likewise clarified. The article inferred that Fiedler's model is profoundly viable and the schooling leaders ought to have exhaustive information on the pertinence of the Fiedler idea. In the event that it is appropriately applied it will be conceivable to accomplish the public objectives in training.

Manoj Kumar Sharma et al (2013) characterized the ideas of Leadership. The characteristic leadership is examined as a result of convictions, character, worth, and morals. The four components of leadership (i.e.) the pioneer, the devotees, the correspondence and the circumstance are additionally clarified. Bass hypothesis of Leadership was portrayed in which it was referenced that how individuals can become leaders by learning the leadership abilities like the Transformational style. Standards of Leadership like knowing thyself, Technical skills, look for and assume liability, Timely choices, act like a model, obliging and capable towards the specialists. Traits of the pioneer are additionally clarified. The jobs and relations between representatives are additionally clarified appropriately thinking about the environment, objectives of the association, estimations of the business. The board and leadership hypotheses are additionally clarified with the foundation of corporate administration, the mental affiliations, Maslow's Triangle of chain of command, love and profound viewpoints. Bolden. R et.al (2013) presents that the movement theory and competency structures that were named to help the movement of the new National Occupational Standards in Management and Leadership. The speculations of Leadership advanced on leadership continuum from the previous seventy years, starts with "Incredible Man" characteristic hypotheses to full reach Leadership. The point is to clarify about utilizing different procedures to build up the main ability inside people, foundations and the connection of the program. It is derived that while this methodology has its characteristics, it prompts to a particularly individualistic considered power and a by and large prescribed approach to manage organization improvement.

Terence et al (2015) nitty gritty different qualities picked by the new corporate Leaders like Steve Jobs, Mark Zuckerberg and Larry Page to take their organizations higher than ever. The reason for this paper is to examine the choices taken by these powerful Leaders which made them unique. The uncommon leadership changed the organizations into profoundly effective elements in the business world. They are all of more than $\$ 100$ billion United States Dollar (USD) worth each. The emphasis of making pioneers instead of bosses is what makes the current age separate from the past time of the different leveled activity. The eagerness to bring down them to accept the risk of others is the core of what the present Leader is seeking after. To have key activity capacities that develop importance, train on steadiness, invigorate inventiveness, to embark to go for a definitive, to give motivation to other people, to unravel the hardest of things and to test the fact of the matter is the essence of the stuff to be an uncommon and reformist Leader of today.

Samuel Kanyandekwe (2012) in their investigation expressed that worker Leadership has a huge connection with work relations. The outcomes depended upon the emotional review done on the subject matter experts and officials of Seventh-day Adventist-Church Institution. Strong association styles turned out to be the littlest utilized action. The results relied upon the emotional audit coordinated on the specialists and officials of Seventh-day Adventist-Church Institution.

James et al (2013) thought that the Transformational and the Transactional Leadership are extraordinary. However, the maker also explained that a couple of segments of Transactional authority exist in the Transformational activity.

Yaser Mansour AL Mansour (2012) thought that Transformational Leadership can be incorporated it if leaders attempt to expand and raise the interests of their subordinates and furthermore make mindfulness and acknowledgment of the association a mission. Value-based activity incorporates pioneer fan exchanges significant for achieving routine execution settled upon among pioneers and followers

\section{Transformational Leadership and Commitment}

May-Chaunlo et al (2014) examined the relationship among the sorts of leadership and worker's responsibility. The result determined is that the majority of the credits of the groundbreaking and Transactional sort of leadership have a critical connection with a level of responsibility.

Samantha C et.al (2014) saw that sexual orientation explicit differentiations are not seen in the adequacy of leadership. This additionally clarified that the men evaluated themselves more viable than ladies.

Nor Famiza, (2014) in the survey on styles of power it was recognized that esteem based organization displayed enormous differentiation amidst age social events. The survey relied upon 201 custodians of four universities in Malaysia. The examination was upheld by University Technology MARA (UiTM), Shah Alam, Malaysia The audit moreover recommended that clerks should apply a grouping of power styles and practices considering the need and situation as they help in better basic reasoning and animate subordinates to be proactive. These various parts can assist them with interfacing with subordinates in the affiliation. 
Khalid Rasheed Memon (2014) reviewed that activity, being the most asked about the purpose of each and every sociological thought is correspondingly of magnificent importance for the affiliations and the specialists. An organized methodology, indicating the relationship among the Leadership Styles and Employee Performance through the mediating some segment of Culture and Gender while Communication tolerating the planning part. Accurate Research of cross-countries needed to be done to center the thoroughness considered Leadership and impacts of different master styles in different social orders and besides sex contrasts.

The degree of assortment, in fact, styles and virtuoso execution arranging of society and sexual introduction complexities may be estimated over the areas o Scientists may discover what kind of style is most considering everything utilized over the domains and end up being useful for getting required boss occurs.

The assessment of Transformational Leadership might be broke down across over countries for their use, adequacy, and change.

Scientists may find, whether or not similar or dissimilar, effects of tantamount/disparate position style in different social orders with same sexual direction and social capacities, on agent execution.

Mohamed Zennouche et al (2014) expected that both association and alliance culture acknowledge key parts in creating progress. This paper separates 12 years of work and diverse leveled culture on development field research in the fundamental eight affiliation journals. The reason for this paper is to pack the affiliation which considers between the two sections to review connection between authoritative culture and action. Through a meaningful assessment, it sets up the relationship among affiliation and legitimate culture. The producers propose that talking several issues in Leadership and different leveled culture that need advance assessment.

Isla Campbell et al (2011) concentrated on Leadership Styles, conduct, and capabilities which included Police power as target respondents gave the accompanying ends. Right off the bat, the policing requests and way to deal with oversee organization and receive those advancements to different divisions, regardless of these and furthermore what is significant is the ability to 'Charge and Control'. Furthermore, a capable police pioneer needs to make participative and solid styles, cutoff points and practices. Finally, a mind blowing police ought to can alter the Leadership style to suit setting and this individual ought to can provide the request, to be dynamic when required.

Michael West et al (2014) contemplated the Leadership needs at National wellbeing administrations associations. Here it needs the way of life with the consideration that ought to be polished at all levels (i.e.) Personal, Group and National levels. Wellbeing administrations need to teach the excellent safe medical care, keeping up common perspective, coordinated effort, high commitment at all levels of the association or more all fitting aggregate Leadership culture can just accomplish this.

FarbodAzar et al (2014) think that effective organization is essential to experiencing obstructions facing the prosperity field. The clarification behind this study was to assess office bosses' drive style through selfassessment and to pick the association between alliance styles with obliging affiliation's experts' imperativeness receptiveness and expert.

Marcus Goncalves (2013) portrayed various frameworks of getting power in an affiliation and the piece of these power in a concise manner for example use or (not to use) these powers in legitimate direct. This paper inspects the strategy of affiliation itself changes into a pass on the program, in a business world stacked with deluding and greed except if pioneers have a concurring story to tell, no one will notice them. With the goal that these days the pioneers are articulating their inside potential into the depicting about the indisputable food.

Vittal S. Anantatmula (2014) investigated the need of leadership in task the executives, built up a model by obviously expressing the parts simultaneously. The job of venture supervisor and different segments can be dissected for powerful execution of activities, where time and cash are enormously included.

Shanta Harper (2012)An undeniable and fundamental planning technique that wraps the essential occupations of various movement styles and the possibility of social affectability will make the immaculate condition for a persuading pioneer mentor, accomplishing a fulfilled customer association that is endless and Transformational. Mentors "work alongside an assortment of customers coming from a wide scope of ventures with a ton of social contrasts". An undeniable and foundational getting ready methodology that wraps the essential businesses of various action styles and the possibility of globalization and social affectability will make the ideal condition for a persuading pioneer mentor, accomplishing a fulfilled customer connection that is endless and Transformational.

R.Gopal et al, (2014) in the examination on the effect of various Leadership Styles and its impact on worker motivation show that both Transformational and Transactional were the basically prevailing Leadership Styles to follow. The outcomes uncover that different styles of Leadership show various effects on representative motivation. The objective gathering for the investigation was the workers of an oil and treatment facility organization. The examination suggested that the leadership ought to involve Transformational and Transactional segments, for example, adhering to run book just as propelling the people.

Wan Omar et al (2013) unquestionably researched the relationship among Transformational affiliation style by drawing in or obliging motivation, wise influencing, and individualized idea with business satisfaction. Right around 100 respondents from one of the shrewd relationship in the country Malaysia esteemed the audit 
intentionally. The data was researched by procedures for congruity factor examination (CFA) using SPSS Amos programming.

\section{Conclusion}

The job of leadership in the present corporate associations has changed. The achievement of any association is generally reliant on an association's supervisory group and the leadership style utilized. Leadership Styles on results like Extra exertion, Effectiveness and Satisfaction is more supported in the Private Sector than public power utilities. Similarly, the rehearsing level of viable Leadership Styles is more in the private power utilities.

\section{REFERENCES}

1. Al- Khasawneh, A. L., and Futa, S. M. (2012). The impact of leadership styles used by the academic staff in the Jordanian public universities on modifying students' behavior: A field study in the northern region of Jordan. International Journal of Business and Management, 8(1), 1.

2. Alloubani, A., Almatari, M., Almukhtar, M. M. (2014). Effects of Leadership styles on quality of services in healthcare. European Scientific Journal, ESJ, 10(18).

3. Almansour, Y. M. (2012). The relationship between leadership styles and motivation of managers conceptual framework. Journal of Arts, Science and Commerce, 3(1), 161-166.

4. Azar, F. E., and Asiabar,A. S. (2015). Does leadership effectiveness correlates with leadership styles in healthcare executives of Iran University of Medical Sciences?. Medical journal of the Islamic Republic of Iran, 29, 166.

5. Bhatti, N., Maitlo, G. M., Shaikh, N., Hashmi, M. A., and Shaikh, F. M. (2012). The impact of autocratic and democratic leadership style on job satisfaction. International Business Research, 5(2), 192.

6. Bosiok, D., and Sad, N. (2013). Leadership styles and creativity. Online Journal of Applied Knowledge Management, 1(2), 64-77.

7. Byrne, B. M., and Van de Vijver, F. J. (2010). Testing for measurement and structural equivalence in large-scale cross-cultural studies: Addressing the issue of non-equivalence. International Journal of Testing, 10(2), 107-132.

8. Drucker, P. (2017). What Makes an Effective Executive (Harvard Business Review Classics). Harvard Business Review Press.

9. Gio, T. H. Y., andYazdanifard, R. (2015). The Unconventional Leadership of Corporate Leaders in the 21st Century. Global Journal of Management And Business Research.

10. Goncalves, M. (2013). Leadership styles: The power to influe

11. Gopal, R., and Chowdhury, R. G. (2014). Leadership styles and employee motivation: An empirical investigation in a leading oil company in India. International journal of research in business management, 2(5), 1-10.

12. Iqbal, J., Inayat, S., Ijaz, M., and Zahid, A. (2012). Leadership styles: Identifying approaches and dimensions of leaders. Interdisciplinary Journal of Contemporary Research in Business, 4(3), 641-659.

13. Koech, P. M., and Namusonge, G. S. (2012). The effect of leadership styles on organizational performance at state corporations in Kenya. International Journal of Business and Commerce, 2(1), 112.

14. Kotur, B. R., and Anbazhagan, S. (2014). The Influence of age and gender on the leadership styles. IOSR Journal of Business and Management, 16(1), 30-36.

15. McCleskey, J. A. (2014). Situational, transformational, and transactional leadership and leadership development. Journal of Business Studies Quarterly, 5(4), 117.

16. Obiwuru, T. C., Okwu, A. T., Akpa, V. O., and Nwankwere, I. A. (2011). Effects of leadership style on organizational performance: A survey of selected small scale enterprises in Ikosi-Ketu council development area of Lagos State, Nigeria. Australian Journal of Business and Management Research, $1(7), 100$.

17. Odumeru, J. A., and Ogbonna, I. G. (2013). Transformational vs. transactional leadership theories: Evidence in literature. International Review of Management and Business Research, 2(2), 355.

18. Omar, W. W. (2013). Transformational leadership style and job satisfaction relationship: A study of structural equation modeling (SEM). International journal of academic research in business and social sciences, 3(2), 346. 